\title{
Factors affecting engineers' acceptance of asynchronous e-learning systems in high-tech companies
}

\author{
Chorng-Shyong Ong ${ }^{\mathrm{a}, 1}$, Jung-Yu Lai ${ }^{\mathrm{a}, *}$, Yi-Shun Wang ${ }^{\mathrm{b}, 2}$ \\ ${ }^{a}$ Department of Information Management, National Taiwan University, No. 50, Lane 144, Sec. 4, Jilung Rd., \\ Daan Chiu, Taipei 106, Taiwan, ROC \\ ${ }^{\mathrm{b}}$ Department of Information Management, National Changhua University of Education, \\ 2 Shi-Da Road, Changhua 500, Taiwan, ROC
}

Received 8 January 2003; received in revised form 10 June 2003; accepted 7 August 2003

Available online 30 October 2003

\begin{abstract}
With the rapid change in all types of working environment, there is a need to implement electronic learning (e-learning) systems to train people in new technologies, products, and services. However, the large investment in e-learning has made user acceptance an increasingly critical issue for technology implementation and management. Although user acceptance received fairly extensive attention in prior research, efforts were needed to examine or validate previous results, especially in different technologies, user populations, and/or organizational contexts. We therefore proposed a new construct, perceived credibility, to examine the applicability of the technology acceptance model (TAM) in explaining engineers' decisions to accept e-learning, and address a pragmatic technology management issue. Based on a sample of 140 engineers taken from six international companies, the results strongly support the extended TAM in predicting engineers' intention to use e-learning.
\end{abstract}

(C) 2003 Elsevier B.V. All rights reserved.

Keywords: E-learning; Perceived credibility; Technology acceptance model (TAM)

\section{Introduction}

The shift from a product-based to a knowledgebased economy has resulted in an increased demand for knowledge workers who are capable of higherorder thinking and reasoning to solve intricate problems in the work place. This requires organizations to

\footnotetext{
* Corresponding author. Tel.: +886-935-697-208; fax: +886-223-621-327.

E-mail addresses: ongcs@im.ntu.edu.tw (C.-S. Ong), roylai@cm1.hinet.net (J.-Y. Lai), keynes@mis.nccu.edu.tw (Y.-S. Wang).

${ }^{1}$ Tel.: +886-2-23630231x2989; fax: +886-2-23621327.

${ }^{2}$ Tel.: +886-4-7232105x7331; fax: +886-4-22599909.
}

educate and train anyone, anytime, and from anywhere. For this task, asynchronous e-learning, defined as instructional content or learning experience delivered or enabled by electronic technologies including the Internet, intranets, and extranets $[16,25]$, breaks the limitations of time and space and also creates many benefits, including reduced cost, regulatory compliance, meeting business needs, retraining of employees, low recurring cost, and customer support $[4,15,17]$. The impact of e-learning is real and it has received fairly extensive attention from practitioners and information system (IS) researchers [31]. Furthermore, analysts forecast that corporate spending on e-learning programs will top US\$ 23 billion by 2004 [21]. 


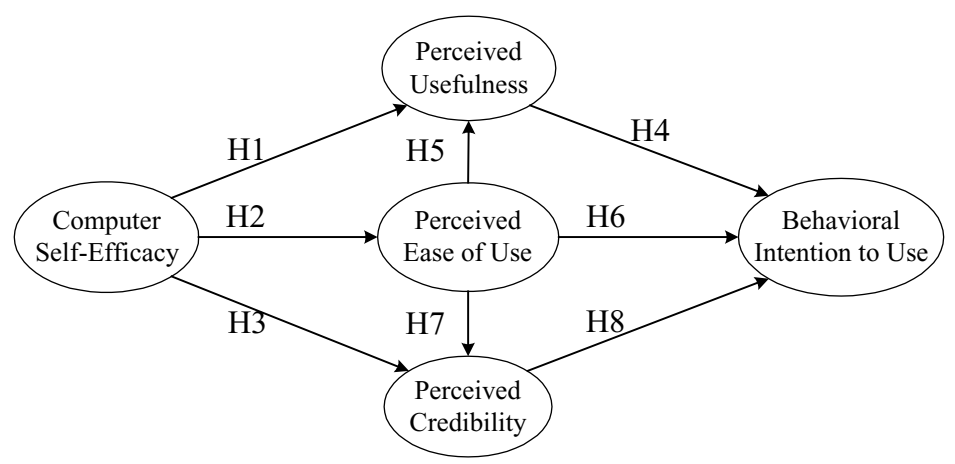

Fig. 1. Research model.

E-learning is reported to be a means of solving learning and performance problems and has become an increasingly critical issue.

Although there have been rapid advances in hardware and software capabilities, the problem of underutilized systems still remains [22,28,29,39]. The technology acceptance model (TAM) [10,11], adapted from theory of reasoned action (TRA) [3,13], has been used as the theoretical basis for many empirical studies of user technology acceptance [33,35,37]. Apparently, it is the most promising way to overcome the problem of underutilized systems. However, e-learning is relatively new and electronic learners (e-learners) are a specific user group. Thus, existing variables of TAM cannot fully reflect e-learners' motives, requiring a search for additional intrinsic motivation factors.

Privacy and security features have been heavily emphasized in the e-commerce context $[5,14,32]$. Protecting private information (e.g., education records ${ }^{3}$ ) will also affect e-learners' willingness to accept elearning. These issues have not yet been empirically examined in an e-learning context. This study was started to respond both to prior studies' indication of the need for a broader exploration of factors beyond the original TAM $[20,23]$ and to a prior study's suggestion for more examination of the role computer self-efficacy plays in predicting IT usage behavior [7]. The study proposes a new construct, "perceived credibility," to enhance understanding of an engineer's acceptance of e-learning. Also, it shows that computer self-efficacy

\footnotetext{
${ }^{3}$ Family Educational Rights and Privacy Act (FERPA) defines educational records as: student's date and place of birth, parent(s) and/or guardian addresses, grades, test scores, courses taken, etc.
}

has a significant effect on behavioral intention to use e-learning.

\section{Theoretical development}

Similar to prior research on TAM $[6,19,24]$, the "attitude" construct was removed to simplify the model. Fig. 1 depicts the research model for the study, excluding actual behavior but expanding computer self-efficacy and perceived credibility. This is based on prior research, which suggested that user acceptance is determined by two key beliefs: perceived usefulness and perceived ease of use. In addition, two variables, computer self-efficacy and perceived credibility were integrated into TAM to adapt it for the empirical study of e-learning.

\subsection{Computer self-efficacy}

In an IS/IT context, computer self-efficacy is defined as "an individual's perceptions of his or her ability to use computers in the accomplishment of a task rather than reflecting simple component skills" [8]. Significant influences of computer self-efficacy on perceived usefulness have been empirically validated. Additionally, the relationship between computer selfefficacy and perceived ease of use was based on theoretical argument [26] and this was empirically examined to see whether there exists a causal link between computer self-efficacy and perceived ease of use $[2,36]$. These suggest that computer self-efficacy has a significant positive effect on perceived ease of use of e-learning. The relationship between computer 
self-efficacy and perceived credibility has not yet been empirically validated, however, Hoffman et al. [18] analysed data from the 1997 CommerceNet/Nielsen Internet Demographic Survey and found that it is apparent that negative perceptions regarding privacy and security increase in conjunction with levels of online proficiency (described here as "computer selfefficacy"). The more experience one acquires online, the more important are concerns of control over personal information, implying that computer self-efficacy will have a negative effect on perceived credibility in an e-learning context. Therefore, we hypothesized:

H1. Computer self-efficacy will have a positive effect on perceived usefulness of e-learning.

H2. Computer self-efficacy will have a positive effect on perceived ease of use of e-learning.

H3. Computer self-efficacy will have a negative effect on perceived credibility of e-learning.

\subsection{Perceived usefulness}

Perceived usefulness is the degree to which a person believes that using a particular system would enhance his or her job performance. Within a high-tech context, engineers are generally reinforced for good performance by raises, promotions, bonuses, etc. This implies that an e-learning system with a high level of perceived usefulness is one for which a user believes that there is a positive user-performance relationship. There is also extensive research in the IS community providing evidences of the effect of perceived usefulness on behavioral intention to use [38]. The ultimate reason that engineers exploit elearning is that they find the system improves their performance. Therefore, we hypothesized:

H4. Perceived usefulness will have a positive effect on the behavioral intention to use e-learning.

\subsection{Perceived ease of use}

Perceived ease of use is the degree to which a person believes that using a particular system would be free of effort. It is expected to influence perceived usefulness, behavioral intention to use, and perceived credibility.
Extensive research over the past decade has provided evidence that perceived ease of use has a significant effect on behavioral intention to use, either directly or indirectly, through its effect on perceived usefulness $[1,34]$. On the other hand, Moon and Kim [27] pointed out that ITs that are easier to use will be less threatening to the individual, implying that perceived ease of use will have a positive effect on users' perceived credibility as interacting with e-learning. Thus, we hypothesized:

H5. Perceived ease of use will have a positive effect on perceived usefulness of e-learning.

H6. Perceived ease of use will have a positive effect on behavioral intention to use e-learning.

H7. Perceived ease of use will have a positive effect on perceived credibility of e-learning.

\subsection{Perceived credibility}

Similar to consumers' concerns, an e-learning system with assurance that users are free of privacy and security threats is expected to affect e-learners' willingness to accept it. Consequently, a new construct, perceived credibility, is proposed to enhance our understanding of a user's acceptance behavior. In contrast to previous research, we used a more limited definition. Perceived credibility was defined as the degree to which a person believed that using a particular system would be free of privacy and security threats. In addition to concerns with perceptions of usefulness and ease of use, behavioral intention to use might be affected by users' perceptions of credible issues about privacy and security in an e-learning context. Thus, we hypothesized:

H8. Perceived credibility will have a positive effect on behavioral intention to use e-learning.

\section{Methodology}

\subsection{Measures}

To ensure content validity of the scales, the items must represent the concept about which generalizations are to be made. Items selected for the constructs were adapted mainly from previous research. 
Computer self-efficacy was measured by four items adapted from Compeau et al. [9]. Items measuring perceived usefulness and perceived ease of use were taken from a previously validated inventory and modified to fit the specific technology. Two statements specifically developed for this study measured perceived credibility. Finally, the items to measure behavioral intention to use were taken from previous application of TAM. The respondents indicated their agreement or disagreement with the survey instruments using a seven-point Likert-type scale. Pre-testing and pilot testing of measures were conducted by selected users from the e-learning field, as well as experts in the area. The items were modified to make them relevant to the e-learning usage context. The Appendix A lists the items used.

\subsection{Subjects}

Data used to test the research model was obtained mainly from six international organizations: Taiwan Semiconductor Manufacturing Corporation (TSMC), United Microelectronics Corporation (UMC), Compal Electronics, Inc., MiTAC International Corporation, Dell Taiwan, and AU Optronics Corporation (AUO). Each company had implemented e-learning and each respondent had experience in using it. The respondents self-administered a 16-item questionnaire. For each question, respondents were asked to circle the response which best described their level of agreement with the statements. Of the 176 surveys, 140 useful responses were returned and thus the response rate was $75.3 \%$. The respondents averaged 31 years in age and had 10 years of experience in computer; the male-tofemale ratio was approximately 1.6 to 1 . Thirty-one percent had completed only one college or university degree; a further 28 percent had completed postgraduate degrees.

\section{Data analysis and results}

\subsection{Analysis of measurement validity}

Measurement validity in terms of reliability and construct validity was evaluated. Reliability of the instrument was evaluated using Cronbach's alpha. All the values were above 0.8 (see Table 1), exceeding
Table 1

Descriptive statistics of items and Cronbach's alpha

\begin{tabular}{llll}
\hline & Mean & S.D. & $\begin{array}{l}\text { Cronbach's } \\
\text { alpha }\end{array}$ \\
\hline Computer self-efficacy (CSE) & & & 0.92 \\
CSE1 & 5.69 & 1.20 & \\
CSE2 & 5.62 & 1.01 & \\
CSE3 & 5.73 & 1.09 & \\
CSE4 & 5.49 & 1.09 & \\
Perceived usefulness (PU) & & & 0.93 \\
PU1 & 5.14 & 1.15 & \\
PU2 & 5.06 & 1.21 & \\
PU3 & 5.00 & 1.16 & \\
PU4 & 5.27 & 1.10 & \\
Perceived ease of use (PEOU) & & & 0.90 \\
PEOU1 & 4.88 & 1.07 & \\
PEOU2 & 4.89 & 1.20 & \\
PEOU3 & 5.02 & 1.15 & \\
PEOU4 & 5.10 & 1.16 & \\
Perceived credibility (PC) & & & 0.87 \\
PC1 & 4.40 & 1.57 & \\
PC2 & 4.01 & 1.67 & \\
Behavioral intention to use (BI) & & & 0.92 \\
BI1 & 5.36 & 1.01 & \\
BI2 & 5.56 & 1.03 & \\
\hline
\end{tabular}

See appendix for abbreviation in Tables $1-3$ and 5.

the common threshold value recommended by Nunnally [30]. A correlation matrix approach and factor analysis were applied to examine the convergent and discriminant validity [12]. As summarized in Table 2, the smallest within-factor correlations are: computer self-efficacy $=0.70$; perceived usefulness $=0.71$; perceived ease of use $=0.54$; perceived credibility $=$ 0.78 ; and behavioral intention to use $=0.85$. In addition, each smallest within-factor correlation was considerably higher among items intended for the same construct than among those designed to measure different constructs. This suggests adequate convergent and discriminant validity of the measurement.

A principal component factor analysis was performed and five constructs were extracted, exactly matching the number of constructs included in the model. As shown in Table 3, there were no crossloading items. Additionally, items intended to measure the same construct exhibited prominently and distinctly higher factor loadings on a single construct than on other constructs, suggesting adequate convergent 
Table 2

Analysis of intermeasurement correlation

\begin{tabular}{|c|c|c|c|c|c|c|c|c|c|c|c|c|c|c|c|c|}
\hline & \multicolumn{4}{|l|}{ CSE } & \multicolumn{4}{|l|}{ PU } & \multicolumn{4}{|c|}{ PEOU } & \multicolumn{2}{|l|}{$\mathrm{PC}$} & \multicolumn{2}{|l|}{ BI } \\
\hline & 1 & 2 & 3 & 4 & 1 & 2 & 3 & 4 & 1 & 2 & 3 & 4 & 1 & 2 & 1 & 2 \\
\hline CSE1 & 1.00 & & & & & & & & & & & & & & & \\
\hline CSE2 & 0.70 & 1.00 & & & & & & & & & & & & & & \\
\hline CSE3 & 0.75 & 0.77 & 1.00 & & & & & & & & & & & & & \\
\hline CSE4 & 0.74 & 0.71 & 0.75 & 1.00 & & & & & & & & & & & & \\
\hline PU1 & 0.39 & 0.41 & 0.37 & 0.51 & 1.00 & & & & & & & & & & & \\
\hline PU2 & 0.37 & 0.31 & 0.30 & 0.46 & 0.79 & 1.00 & & & & & & & & & & \\
\hline PU3 & 0.33 & 0.35 & 0.28 & 0.42 & 0.74 & 0.83 & 1.00 & & & & & & & & & \\
\hline PU4 & 0.39 & 0.40 & 0.41 & 0.44 & 0.71 & 0.76 & 0.76 & 1.00 & & & & & & & & \\
\hline PEOU1 & 0.28 & 0.31 & 0.31 & 0.31 & 0.55 & 0.55 & 0.55 & 0.56 & 1.00 & & & & & & & \\
\hline PEOU2 & 0.41 & 0.35 & 0.32 & 0.37 & 0.47 & 0.47 & 0.48 & 0.48 & 0.54 & 1.00 & & & & & & \\
\hline PEOU3 & 0.46 & 0.40 & 0.41 & 0.45 & 0.52 & 0.54 & 0.53 & 0.50 & 0.67 & 0.80 & 1.00 & & & & & \\
\hline PEOU4 & 0.45 & 0.44 & 0.42 & 0.45 & 0.54 & 0.56 & 0.57 & 0.58 & 0.60 & 0.74 & 0.79 & 1.00 & & & & \\
\hline PC1 & 0.16 & 0.08 & 0.03 & 0.08 & 0.28 & 0.37 & 0.34 & 0.37 & 0.38 & 0.47 & 0.47 & 0.46 & 1.00 & & & \\
\hline $\mathrm{PC} 2$ & 0.18 & 0.02 & 0.04 & 0.11 & 0.29 & 0.37 & 0.28 & 0.33 & 0.37 & 0.42 & 0.42 & 0.36 & 0.78 & 1.00 & & \\
\hline BI1 & 0.32 & 0.34 & 0.27 & 0.32 & 0.43 & 0.52 & 0.45 & 0.48 & 0.41 & 0.40 & 0.48 & 0.47 & 0.40 & 0.43 & 1.00 & \\
\hline BI2 & 0.37 & 0.40 & 0.36 & 0.34 & 0.45 & 0.51 & 0.46 & 0.53 & 0.42 & 0.44 & 0.51 & 0.53 & 0.40 & 0.41 & 0.85 & 1.00 \\
\hline
\end{tabular}

Table 3

Factor analysis results: principal component extraction

\begin{tabular}{|c|c|c|c|c|c|}
\hline & \multicolumn{5}{|c|}{ Factor } \\
\hline & 1 & 2 & 3 & 4 & 5 \\
\hline \multicolumn{6}{|c|}{ Computer self-efficacy (CSE) } \\
\hline CSE1 & 0.17 & 0.86 & 0.14 & 0.10 & 0.14 \\
\hline CSE2 & 0.19 & 0.83 & 0.15 & 0.22 & -0.08 \\
\hline CSE3 & 0.17 & 0.88 & 0.13 & 0.13 & -0.05 \\
\hline CSE4 & 0.14 & 0.83 & 0.31 & 0.08 & 0.02 \\
\hline \multicolumn{6}{|c|}{ Perceived usefulness (PU) } \\
\hline PU1 & 0.23 & 0.26 & 0.81 & 0.15 & 0.10 \\
\hline PU2 & 0.20 & 0.17 & 0.85 & 0.23 & 0.19 \\
\hline PU3 & 0.26 & 0.14 & 0.85 & 0.18 & 0.10 \\
\hline PU4 & 0.22 & 0.24 & 0.77 & 0.24 & 0.16 \\
\hline \multicolumn{6}{|c|}{ Perceived ease of use (PEOU) } \\
\hline PEOU1 & 0.62 & 0.10 & 0.45 & 0.16 & 0.14 \\
\hline PEOU2 & 0.79 & 0.21 & 0.21 & 0.14 & 0.27 \\
\hline PEOU3 & 0.81 & 0.26 & 0.26 & 0.21 & 0.23 \\
\hline PEOU4 & 0.74 & 0.27 & 0.33 & 0.23 & 0.18 \\
\hline \multicolumn{6}{|c|}{ Perceived credibility (PC) } \\
\hline PC1 & 0.27 & -0.02 & 0.16 & 0.17 & 0.86 \\
\hline $\mathrm{PC} 2$ & 0.16 & 0.01 & 0.15 & 0.19 & 0.90 \\
\hline \multicolumn{6}{|c|}{ Behavioral intention to use (BI) } \\
\hline BI1 & 0.17 & 0.15 & 0.25 & 0.88 & 0.21 \\
\hline $\mathrm{BI} 2$ & 0.22 & 0.21 & 0.24 & 0.86 & 0.18 \\
\hline
\end{tabular}

and discriminant validity. The observed reliability and convergent/discriminant validity suggested adequacy of the measurements used in the study.

\subsection{Model testing results}

The hypothesized relationships were tested using the CALIS procedure of SAS 8.1. This provides estimates of parameters and tests of fit for linear structural equation model similar to LISREL. All seven common goodness-of-fit indexes, summarized in Table 4, exceeded their respective common acceptance levels, suggesting that the research model exhibited a good fit with the data.

Properties of the causal paths, including standardized path coefficients, $P$-values, and variance explained for each equation in the hypothesized model are presented in Fig. 2. As expected, computer self-efficacy had a significant positive effect on both perceived usefulness (beta $=0.17, P<0.05$ ) and perceived ease of use (beta $=0.54, P<0.001$ ), whereas it had a significant negative effect on perceived credibility (beta $=-0.28$, $P<0.01$ ). Therefore, hypotheses $\mathrm{H} 1, \mathrm{H} 2$, and $\mathrm{H} 3$ were supported. Computer self-efficacy explained 30 percent of the variance in perceived ease of use. The total effect 
Table 4

Goodness-of-fit measures of the research model

\begin{tabular}{lll}
\hline $\begin{array}{l}\text { Goodness-of-fit } \\
\text { measure }\end{array}$ & $\begin{array}{l}\text { Recommended } \\
\text { value }\end{array}$ & $\begin{array}{l}\text { Model } \\
\text { statistic }\end{array}$ \\
\hline Chi-square/degree of freedom & $\leq 3.00$ & 1.34 \\
Goodness-of-fit index (GFI) & $\geq 0.90$ & 0.90 \\
Adjusted goodness-of-fit index (AGFI) & $\geq 0.80$ & 0.85 \\
Normalized fit index (NFI) & $\geq 0.90$ & 0.93 \\
Nonnormalized fit index (NNFI) & $\geq 0.90$ & 0.98 \\
Comparative fit index (CFI) & $\geq 0.90$ & 0.98 \\
Root mean square residual (RMSR) & $\leq 0.10$ & 0.04 \\
\hline
\end{tabular}

of computer self-efficacy on behavioral intention to use was 0.33 .

Perceived usefulness had a significant positive effect on behavioral intention to use (beta $=0.34$, $P<0.01)$ and $50 \%$ of the variance in perceived usefulness was explained by computer self-efficacy and perceived ease of use. Perceived ease of use was found to be a significant factor in determining perceived usefulness (beta $=0.60, \quad P<0.001$ ), behavioral intention to use (beta $=0.26, P<0.05$ ), and perceived credibility (beta $=0.72, P<0.001$ ). Thus, hypotheses H4, H5, H6, and $\mathrm{H} 7$ were supported. Finally, perceived credibility had a positive effect on behavioral intention to use (beta $=0.20, P<0.05$ ) and $38 \%$ of the variance in perceived credibility could be explained by computer self-efficacy and perceived ease of use. Therefore, hypothesis H8 was supported.

The proposed model accounted for $44 \%$ of the variance in behavioral intention to use. According to the path coefficients, perceived usefulness exhibited the strongest direct effect on behavioral intention to use. Perceived ease of use, despite showing a slightly weaker direct effect than perceived usefulness on behavioral intention to use, exhibited a stronger total effect on behavioral intention to use than that of perceived usefulness. The total effect of perceived ease of use on behavioral intention to use was 0.61. The direct, indirect, and total effect of computer selfefficacy, perceived usefulness, perceived ease of use, and perceived credibility on behavioral intention to use were summarized in Table 5.

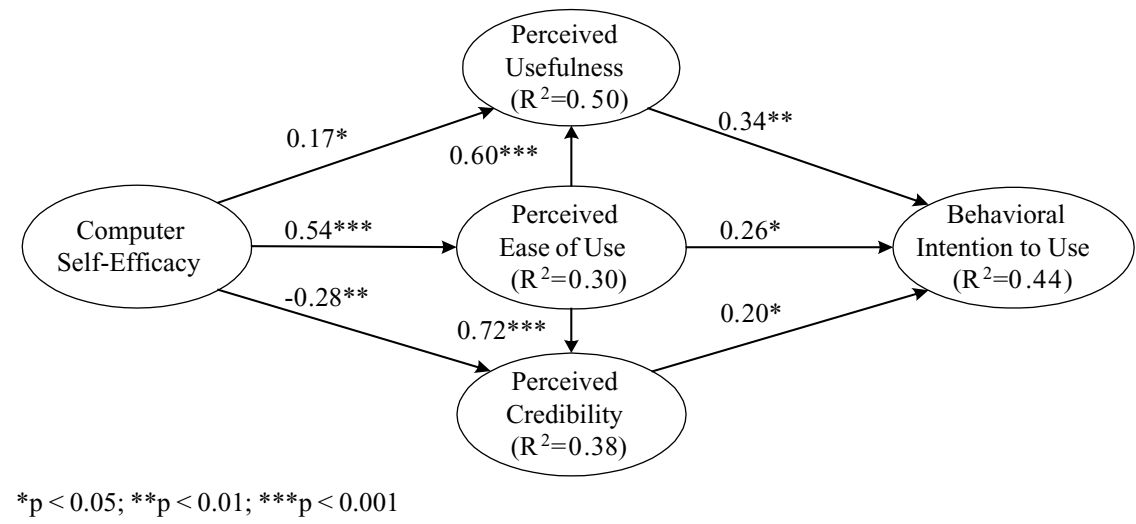

Fig. 2. Model testing results: ${ }^{*} P<0.05 ;{ }^{* *} P<0.01 ;{ }^{* * *} P<0.001$.

Table 5

The direct, indirect, and total effect of dominants on behavioral intention to use

\begin{tabular}{|c|c|c|c|c|c|c|c|c|c|c|c|c|}
\hline & \multicolumn{4}{|c|}{ Direct effect } & \multicolumn{4}{|c|}{ Indirect effect } & \multicolumn{4}{|c|}{ Total effect } \\
\hline & PU & PEOU & $\mathrm{PC}$ & $\mathrm{BI}$ & $\mathrm{PU}$ & PEOU & $\mathrm{PC}$ & BI & PU & PEOU & $\mathrm{PC}$ & BI \\
\hline CSE & 0.17 & 0.54 & -0.28 & & 0.32 & & 0.39 & 0.33 & 0.49 & 0.54 & 0.11 & 0.33 \\
\hline PU & & & & 0.34 & & & & & & & & 0.34 \\
\hline PEOU & 0.60 & & 0.72 & 0.26 & & & & 0.35 & 0.60 & & 0.72 & 0.61 \\
\hline $\mathrm{PC}$ & & & & 0.20 & & & & & & & & 0.20 \\
\hline
\end{tabular}




\section{Discussion}

Computer self-efficacy appeared to be a significant determinant of perceived usefulness, perceived ease of use, and perceived credibility. Users who have higher computer self-efficacy are likely to have more positive usefulness and ease of use beliefs. This finding also supports prior research. However, computer self-efficacy had a negative effect on perceived credibility. Possibly an individual with high computer self-efficacy may see the limitations and lack of privacy and security of a particular e-learning system. The higher the computer self-efficacy of an engineer, the more skepticism she or he may have. Although computer self-efficacy had a negative effect on perceived credibility, its total effect on perceived credibility and behavioral intention to use was still positive.

Judged by its direct effect on behavioral intention to use, perceived usefulness was found to be the most significant factor affecting users' acceptance of e-learning. It seems that engineers have specialized training and practice in a highly autonomous profession. Thus, an essential acceptance criterion is whether or not the e-learning system provides useful content for filling the needs of an individual professional. The evaluation criterion or rationale may be, in part, rooted in engineers' tendency to view the e-learning system as a tool, acceptable only when proven to provide desired utility to them. Pedagogical principles, including principles of developing content and packaging content, could be employed in the development and evaluation of useful content.

Perceived ease of use was found to have the most significant effect on behavioral intention to use. This suggests that a user's belief of ease of use is a crucial antecedent to her or his perceptions of usefulness and credibility of e-learning. As expected, perceived credibility was found to be another important factor influencing users' intention to use e-learning, indicating that it is not sufficient to develop an e-learning system with valuable functions and user-friendly interaction to attract more users to use. It is of paramount importance to develop e-learning with a trustworthy protection of education records to assure e-learners that they are free of privacy and security threats. Education records are of importance and sensitivity to e-learners.

\section{Conclusions}

Using the extended model as a theoretical framework, this study helps practitioners and researchers better understand why people resist using e-learning, predict how users will respond to e-learning, and increase user acceptance by improving the techniques and processes by which they are implemented. Also, it can help researchers considerate our findings for development and evaluation of e-learning theories.

Major contributions are:

1. Our results demonstrate how perceived credibility influences users' attitudes toward using e-learning: they must assure e-learners that they are free of privacy and security threats.

2. Perceived usefulness has the most significant direct effect on behavioral intention to use e-learning: they must provide useful content to attract 'pragmatic' users to use.

3. Perceived ease of use was found to be an important antecedent of perceived usefulness and perceived credibility. User-friendliness is also important for the success of e-learning and will increase e-learners' perceptions of perceived usefulness and perceived credibility.

4. TAM has been extended in an e-learning context.

5. Computer self-efficacy had a positive effect on perceived usefulness and perceived ease of use, whereas it had a negative effect on perceived credibility.

Four limitations of this study should be noted. First, investigating acceptance of e-learning is relatively new. The findings and their implications are obtained from a single study of a particular technology in Taiwan. Thus, caution needs to be taken when generalizing our findings. Second, responses were voluntary and thus inevitably subject to self-selection biases. Conceivably, users who were interested in, had used, or were currently using e-learning were more likely to respond. Third, the R-square reported by the current research represents another limitation: there may be a need to search for additional variables (e.g., subjective norm, gender, internet experience, level of education) to improve our ability to predict usage intentions more accurately. Finally, the study was conducted with a snapshot research approach. Additional efforts are 
needed to evaluate the validity of the proposed model and our findings.

There are several implications for e-learning management based on our findings.

1. It is important for e-learning to be useful by enhancing the recipient's job performance or productivity.

2. Although perceived usefulness was the most significant direct effect on behavioral intention to use, perceived ease of use has a stronger total effect than perceived usefulness. Therefore, being a user-friendly system is also important for its success.

3. This study confirms the significant influence of perceived credibility on behavioral intention to use e-learning. It must assure e-learners that they are free of privacy and security threats. In addition, perceived credibility seems to influence users' attitudes toward using e-learning.

4. Perceived usefulness, perceived ease of use, and perceived credibility are more "system-specific" in the sense that they refer to the perceptions of a particular system, whereas computer self-efficacy as examined here is more general. Managers and developers can increase users' usage intention through this. In businesses, human resource managers can provide training courses to increase employees' familiarity with computing technologies. Such education need not be formal and may take any form (e.g., seminars and informal discussions).

\section{Appendix A}

Computer self-efficacy (CSE)

I could complete my learning activities using the e-learning system...

CSE1 ...if I had never used a system like it before.

CSE2 ...if I had only the system manuals for reference.

CSE3 ...if I had seen someone else using it before trying it myself.

CSE4 ...if I had just the built-in-help facility for assistance.
Perceived usefulness (PU)

PU1 Using the e-learning system improves my job performance.

PU2 Using the e-learning system enhances my effectiveness in my job.

PU3 Using the e-learning system in my job improves my productivity.

PU4 I find the e-learning system to be useful in my job.

Perceived ease of use (PEOU)

PEOU1 My intention with the e-learning system is clear and understandable.

PEOU2 Interacting with the e-learning system does not require a lot of my mental effort.

PEOU3 I find the e-learning system to be easy to use.

PEOU4 I found it easy to get the e-learning system to do what I want it to do.

Perceived credibility (PC)

PC1 I don't worry about the security issue of the e-learning system.

PC2 I don't worry about the e-learning system divulging my personal information.

Behavioral intention to use (BI)

BI1 Assuming that I had access to the e-learning system, I intend to use it.

BI2 Given that I had access to the e-learning system, I predict that I would use it.

\section{References}

[1] R. Agarwal, J. Prasad, Are individual differences germane to the acceptance of new information technologies? Decision Sciences 30 (2), 1999, pp. 361-391.

[2] R. Agarwal, V. Sambamurthy, R.M. Stair, Research report: the evolving relationship between general and specific computer self-efficacy-an empirical assessment, Information Systems Research 11 (4), 2000, pp. 418-430.

[3] I. Ajzen, M. Fishbein, Understanding attitudes and predicting social behavior, Prentice-Hall, Englewood Cliffs, NJ, 1980.

[4] T. Barron, Getting IT support for e-learning, Training and Development 54 (12), 2000, pp. 32-37. 
[5] F. Belanger, J.S. Hiller, W.J. Smith, Trustworthiness in electronic commerce: the role of privacy, security, and site attributes, Journal of Strategic Information Systems 11 (3-4), 2002, pp. 245-270.

[6] P.Y.K. Chau, An empirical assessment of a modified technology acceptance model, Journal of Management Information Systems 13 (2), 1996, pp. 185-204.

[7] P.Y.K. Chau, Influence of computer attitude and self-efficacy on IT usage behavior, Journal of End User Computing 13 (1), 2001, pp. 26-33.

[8] D.R. Compeau, C.A. Higgins, Computer self-efficacy: development of a measure and initial test, MIS Quarterly 19 (2), 1995, pp. 189-211.

[9] D.R. Compeau, C.A. Higgins, S. Huff, Social cognitive theory and individual reactions to computing technology: a longitudinal study, MIS Quarterly 23 (2), 1999, pp. 145158.

[10] F.D. Davis, Perceived usefulness, perceived ease of use, and user acceptance of information technology, MIS Quarterly 13 (3), 1989, pp. 318-339.

[11] F.D. Davis, R.P. Bagozzi, P.R. Warshaw, User acceptance of computer technology: a comparison of two theoretical models, Management Science 35 (8), 1989, pp. 982-1003.

[12] W.J. Doll, G. Torkzadeh, The measurement of end-user computing satisfaction, MIS Quarterly 12 (2), 1988, pp. 259274.

[13] M. Fishbein, I. Ajzen, Belief, attitude, intention and behavior: an introduction to theory and research, Addison-Wesley, Reading, MA, 1975.

[14] B. Friedman, P.H. Kahn Jr., D.C. Howe, Trust online, Communications of the ACM 43 (12), 2000, pp. 34-40.

[15] J. Gordon, E-learning Tagged as Best Corporate IT Investment, E-learning 4 (1), 2003, pp. 8.

[16] T. Govindasamy, Successful implementation of e-learning pedagogical considerations, Internet and Higher Education 4 (3/4), 2002, pp. 287-299.

[17] M.H. Harun, Integrating e-learning into the workplace, Internet and Higher Education 4 (3/4), 2002, pp. 301-310.

[18] D.L. Hoffman, T.P. Novak, M. Peralta, Building consumer trust online, Communications of the ACM 42 (4), 1999, pp. $80-85$.

[19] W. Hong, J.Y.L. Thong, W.M. Wong, K.Y. Tam, Determinants of user acceptance of digital libraries: an empirical examination of individual differences and system characteristics, Journal of Management Information Systems 18 (3), 2001, pp. 97-124.

[20] P.J. Hu, P.Y.K. Chau, O.R. Liu Sheng, K.Y. Tam, Examining the technology acceptance model using physician acceptance of telemedicine technology, Journal of Management Information Systems 16 (2), 1999, pp. 91-112.

[21] J. Ismail, The design of an e-learning system beyond the hype, Internet and Higher Education 4 (3/4), 2002, pp. 329336.

[22] R. Johansen, R. Swigart, Upsizing the Individual in the Downsizing Organization: Managing in the Wake of Reengineering, Globalization, and Overwhelming Technological Change, Addison-Wesley, Reading, MA, 1996.
[23] P. Legris, J. Ingham, P. Collerette, Why do people use information technology? A critical review of the technology acceptance model, Information and Management 40 (3), 2003, pp. 191-204.

[24] H.P. Lu, D.H. Gustafson, An empirical study of perceived usefulness and perceived ease of use on computerized support system use over time, International Journal of Information Management 14 (5), 1994, pp. 317-329.

[25] C. MacGregor, T. Whittingham, E-learning for industry: the competitive advantage, in: Proceedings of Vocational Education and Training Research Conference, Deakin University, Geelong, July 2001.

[26] K. Mathieson, Predicting user intentions: comparing the technology acceptance model with the theory of planned behavior, Information Systems Research 2 (3), 1991, pp. 173191.

[27] J.W. Moon, Y.G. Kim, Extending the TAM for a World-WideWeb context, Information and Management 38 (4), 2001, pp. 217-230.

[28] G.C. Moore, I. Benbasat, Development of instrument to measure the perceptions of adopting an information technology innovation, Information Systems Research 2 (3), 1991, pp. 192-222.

[29] D.A. Norman, Things That Make us Smart: Defending Human Attributes in the Age of the Machine, AddisonWesley, Reading, MA, 1993.

[30] J.C. Nunnally, Psychometric Theory, second ed., McGrawHill, New York, 1978.

[31] A. Ravenscroft, M.P. Matheson, Developing and evaluating dialogue games for collaborative e-learning, Journal of Computer Assisted Learning 18 (1), 2002, pp. 93-101.

[32] V. Shankar, G.L. Urban, F. Sultan, Online trust: a stakeholder perspective, concepts, implications, and future directions, Journal of Strategic Information Systems 11 (3/4), 2002, pp. 325-344.

[33] S. Taylor, P.A. Todd, Understanding information technology usage: a test of competing models, Information Systems Research 6 (2), 1995, pp. 144-176.

[34] V. Venkatesh, Creation of favorable user perceptions: exploring the role of intrinsic motivation, MIS Quarterly 23 (2), 1999, pp. 239-260.

[35] V. Venkatesh, Determinants of perceived ease of use: integrating control, intrinsic motivation, and emotion into the technology acceptance model, Information Systems Research 11 (4), 2000, pp. 342-365.

[36] V. Venkatesh, F.D. Davis, A model of the antecedents of perceived ease of use: development and test, Decision Sciences 27 (3), 1996, pp. 451-481.

[37] V. Venkatesh, F.D. Davis, A theoretical extension of the technology acceptance model: four longitudinal field studies, Management Science 46 (2), 2000, pp. 186-204.

[38] V. Venkatesh, M.G. Morris, Why don't men ever stop to ask for directions? Gender, social influence, and their role in technology acceptance and usage behavior, MIS Quarterly 24 (1), 2000, pp. 115-139.

[39] L.R. Weiner, Digital Woes: Why We Should Not Depend on Software, Addison-Wesley, Reading, MA, 1993. 


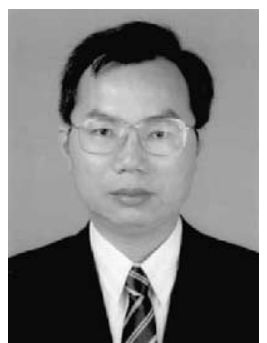

Chorng-Shyong Ong is an associate professor of Information Management at National Taiwan University (NTU), Taiwan. He holds a master's degree in management science and policy studies at TSUKUBA University in Japan. He received his $\mathrm{PhD}$ in business administration from NTU. His research interests include IS service quality, web-based services, electronic commerce and strategic management of e-business. He has published papers in Journal of Information Management, Journal of Quality, Journal of Management \& Systems, NTU Management Review, Sun Yat-Sen Management Review, and other journals.

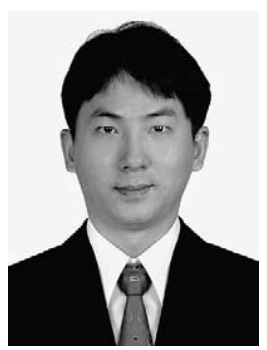

Jung-Yu Lai is a doctoral student of information management at National Taiwan University, Taiwan. He received his MBA in management information systems from National Sun Yat-sen University, Taiwan. He was previously a senior software engineer at the United
Microelectronics Corporation (UMC) in Taiwan. His current research interests include enterprise resource planning, e-business, e-learning, service marketing, and knowledge management.

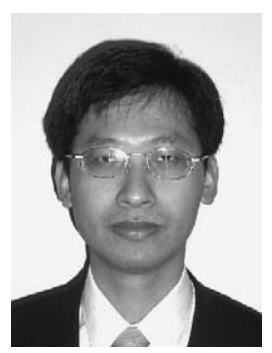

Yi-Shun Wang is an Assistant Professor of information management at National Changhua University of Education, Taiwan. He received his BBA and MBA degrees in information management from National Sun Yat-sen University, and his $\mathrm{PhD}$ in MIS from National Chengchi University in Taiwan. His current research interests include IT/IS adoption strategy, electronic commerce, customer relationship management, and e-learning. Dr. Wang's research is published or is forthcoming in Information \& Management, International Journal of Service Industry Management, Government Information Quarterly, Journal of End User Computing, Journal of Electronic Commerce Research, International Journal of Electronic Business, and a number of national and international conference proceedings. 